Received 07/20/2021

Review began 07/29/2021

Review ended 08/28/2021

Published 08/30/2021

๑) Copyright 2021

Patel et al. This is an open access article distributed under the terms of the Creative Commons Attribution License CC-BY 4.0., which permits unrestricted use, distribution, and reproduction in any medium, provided the original author and source are credited.

\section{The Use of Electrical Nerve Stimulation to Treat Migraines: A Systematic Review}

Karan Patel $^{1}$, Sai Batchu ${ }^{1}$, Rebecca Wang ${ }^{2}$, Sean Bunachita ${ }^{3}$, Aditya Joshi ${ }^{1,4}$, Ria Soni ${ }^{5}$, Aadi Pandya ${ }^{6}$, Urvish Patel $^{7}$

1. Medicine, Cooper Medical School of Rowan University, Camden, USA 2. Medicine, Hackensack Meridian School of Medicine, Nutley, USA 3. Medicine, Johns Hopkins University School of Medicine, Baltimore, USA 4. Orthopaedics, Cooper Medical School of Rowan University, Camden, USA 5. Medicine, Rutgers University, New Brunswick, USA 6. Medicine, Herricks High School, New Hyde Park, USA 7. Epidemiology and Public Health, Icahn School of Medicine at Mount Sinai, New York, USA

Corresponding author: Karan Patel, karanpatel122397@gmail.com

\section{Abstract}

Migraines have been defined as an intense unilateral throbbing or pulsating sensation lasting anywhere between a few hours to multiple days. They are the sixth most prevalent disease in the United States, with approximately $18 \%$ of women and $6 \%$ of men experiencing some form of a migraine throughout their lifetime. In addition, they pose a significant economic burden, accounting for anywhere between $\$ 13$ and $\$ 17$ billion in medical costs annually in the United States. While there are a wide variety of treatments for migraines on the market, such as nonsteroidal anti-inflammatory drugs (NSAIDS), beta-blockers, and antiepileptics, there is still no standard treatment. Moreover, each of these medications has a wide range of side effects, ranging from stomach ulcers to light-headedness. Within the last few decades, the presence of electrical nerve stimulation has emerged as a possible treatment option. These methods are almost free of harmful side effects and may be able to reduce the economic burden on those who suffer from migraines. However, studies have shown mixed results in regard to their efficacy. In this paper, we performed a systematic review to detail the current state of the literature regarding electrical nerve stimulation as a treatment modality for migraines.

Categories: Pain Management, Preventive Medicine, Therapeutics

Keywords: migraine disorder, transcutaneous electrical nerve stimulation, vagus nerve stimulation, occipital nerve stimulation, percutaneous electrical nerve stimulation, trigeminal nerve stimulation

\section{Introduction And Background}

Like most disorders, there appear to be both environmental and genetic factors that may account for the pathophysiology of migraines. A study conducted by Russel et al. showed that there was a higher rate of migraines among monozygotic twins than those experienced by dizygotic twins [1]. In addition, various mutations have been linked with different types of headaches. For example, a mutation in methylenetetrahydrofolate reductase, C667T, has been associated with aura positive migraines. Moreover, variations in chromosome 19p13, in the CACNA1A gene coding for a voltage-gated calcium channel, and mutations in the ATP1A2 gene have been found to be linked to familial hemiplegic migraines [1]. Environmental triggers of migraines include a wide variety of factors but are relatively shared among those who experience migraine attacks. These include, but are not limited to, bright lights, flickering lights, air quality changes, and odors [2].

Although the exact mechanism of migraines is not completely understood, there has been some progress made over the last few decades. Because vasoconstrictors had been shown to relieve migraine symptoms, it was previously postulated that migraines were a result of vasodilation [3]. However, more recent evidence has suggested that migraine pathophysiology may be far more nuanced than previously expected. The current understanding is that a pathway starting with afferent fibers from the occipital branch of the trigeminal nerve which eventually leads to third-order neurons from the basal ganglia, thalamus, hypothalamus synapsing onto cortical areas may be responsible for causing many of the migraine-related symptoms [4]. Moreover, even though migraines are common, various factors can also complicate their diagnosis. For example, cervicogenic headaches are often misdiagnosed as migraines. These headaches occur because of referred pain from the neck and share many features with migraine symptoms including unilateral head pain, photophobia, nausea, and vomiting [5]. Although we have made significant strides in our understanding of the pathophysiology and our ability to distinguish migraines from other similar headaches, more research still needs to be done to determine the precise mechanism of migraines and further distinguishing symptoms separating various types of headaches.

Despite the fact that current medications such as nonsteroidal anti-inflammatory drugs (NSAIDs) and topiramate have proved effective in treating migraine disorders, they also come with a high financial cost and a wide array of side effects [6,7]. As a result, there continues to remain an investigation into other treatment modalities for migraines and their associated symptoms. One potential affordable therapeutic 


\section{Cureus}

alternative may be electrical nerve stimulation (ENS). This treatment modality, which has various subclasses, delivers a voltage-driven electrical signal to a specific region of the body (which changes based on the type of ENS used). Essentially, this voltage-based impulse is thought to modulate the activity of various neurotransmitters including serotonin, gamma-aminobutyric acid (GABA), dopamine, and others. The electrical modulation of neurotransmitters changes the pattern of firing of neurons and can modulate pain, frequency, and other factors classically associated with migraines [8]. An example of a transcutaneous electrical nerve stimulator, one subcategory of electrical nerve stimulators, can be seen in Figure 1 .

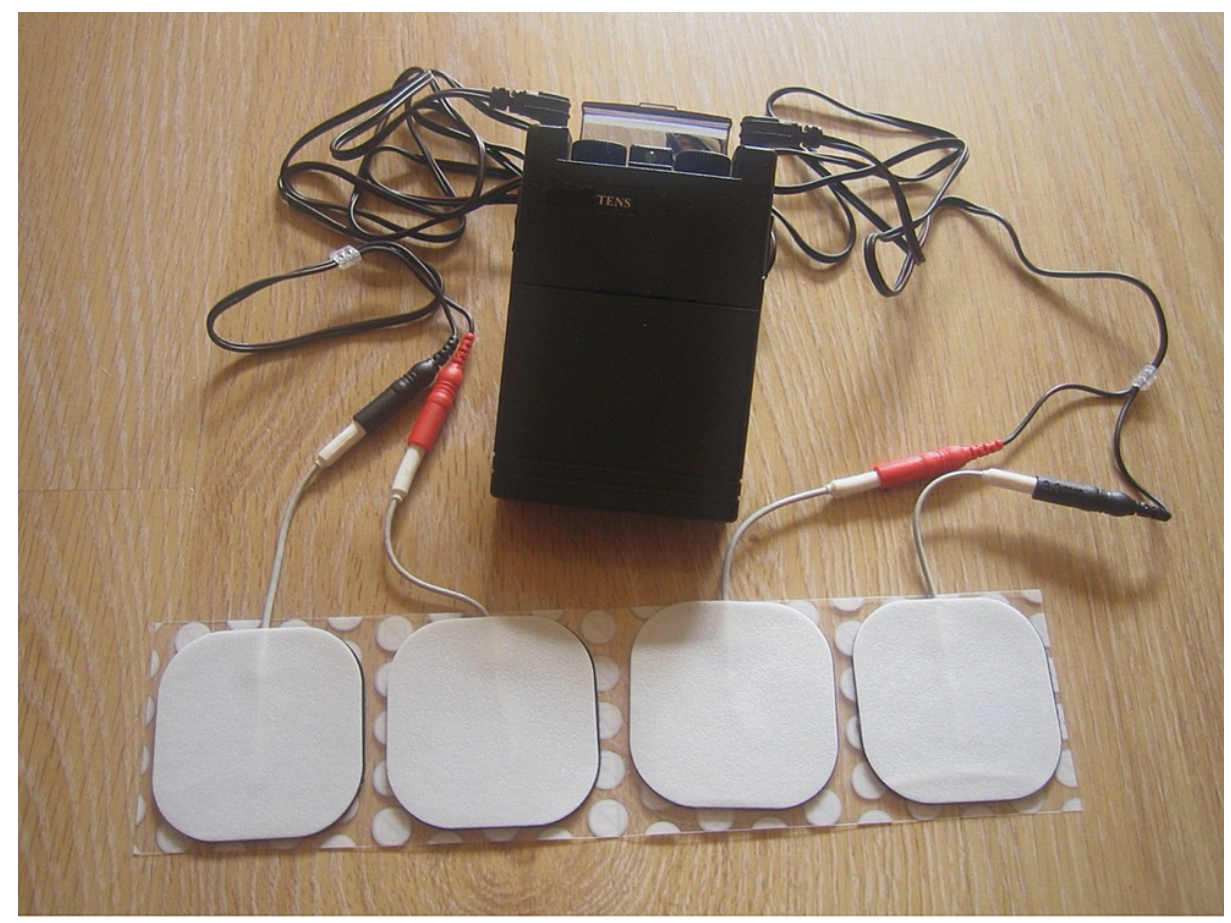

\section{FIGURE 1: Transcutaneous electrical nerve stimulator}

Original image by Wikipedia user Yeza, distributed under a CC BY-SA 4.0 license. No modifications were made [9].

The studies on ENS have shown to have mixed results, with some studies demonstrating that they are effective, while others have shown that they were no more effective than sham treatments [10-12]. Yet recently, there have been some studies that have shown ENS to be effective from a neurological perspective. A study conducted by Zhang et al. found that there was a significant decrease in pain regions of the brain such as the locus coeruleus, in patients who received ENS as an adjunct treatment for their chronic migraines compared to those who received the sham treatment [13]. In addition, in a follow-up study, with an altered protocol, Zhang et al.'s fMRI study showed that transcutaneous auricular vagus nerve stimulation modulates the activity of thalamic circuits in patients suffering from migraines. Moreover, a recent study showed ENS can decrease pro-inflammatory cytokines, more specifically interleukin-1 $\beta$ (IL-1 $\beta$ ), which have been shown to be elevated in some types of headaches [11,14]. These results prove encouraging in that they demonstrate both a cortical and chemical basis for the use of ENS in treating migraines.

In our study, we performed a systematic review of randomized controlled trials (RCTs) of ENS over the last five years. More specifically, we looked into studies that used various forms of ENS including occipital nerve stimulation (ONS), transcutaneous electrical nerve stimulation (TENS), vagus nerve stimulation (VNS) trigeminal nerve stimulation (TNS), and percutaneous electrical nerve stimulation (PENS). We wanted to determine if improvements in technologies combined with our increased knowledge on the pathophysiology of migraines over the last half decade have now allowed for ENS to become a viable alternative treatment for migraines.

\section{Review}

\section{Methods}

We searched the MEDLINE database using PubMed. In addition, we searched the Embase, MEDLINE, and ClinicalTrials.gov databases using The Cochrane Library for RCTs with the search terms Electrical nerve stimulation OR ENS AND migraines, Occipital nerve stimulation or ONS AND migraines, Transcutaneous electrical nerve stimulation or TENS AND migraines, Vagus nerve stimulation AND migraines, Trigeminal 


\section{Cureus}

nerve stimulation AND migraines, and Percutaneous electrical nerve stimulation OR PENS AND migraines. Outside of our manual search, we used SWIFT-Review to supplement the systematic review of clinical trials with ENS and migraines appearing in PubMed-indexed peer-reviewed literature [15]. Our reason behind only including studies from 2015 to 2021 was that we wanted to assess the current state of ENS in the treatment of migraines. Over the last three decades, the data on ENS as a treatment modality has been inconclusive with some studies showing that they have a positive impact, while other studies having found them to be no more beneficial than control sham treatments [10-12]. With the ever-evolving technologies, we aimed to assess if improvements in electrical nerve stimulators over the last five years have now allowed for them to serve as viable treatment options for migraines.

We included papers with the following criteria:

Population: Any person above the age of 18 who experiences migraines.

Intervention: Use of ENS.

Comparison: ENS versus sham or subthreshold stimulation.

Outcome: ENS effect on number, frequency, or severity of migraines compared to sham treatments.

A full list of our search strategy, with details on the articles that we included/excluded, can be seen below in Figure 2, which was generated using Prisma protocol [16]. In addition, Table 1 provides a comprehensive summary of each of the RCTs that we included in our study and their primary results. In order to assess each of the studies for potential bias, we used the Cochrane Collaboration's risk of bias tool and included our justification for any category we deemed to have anything other than low bias at the bottom of the Table 2 [17].
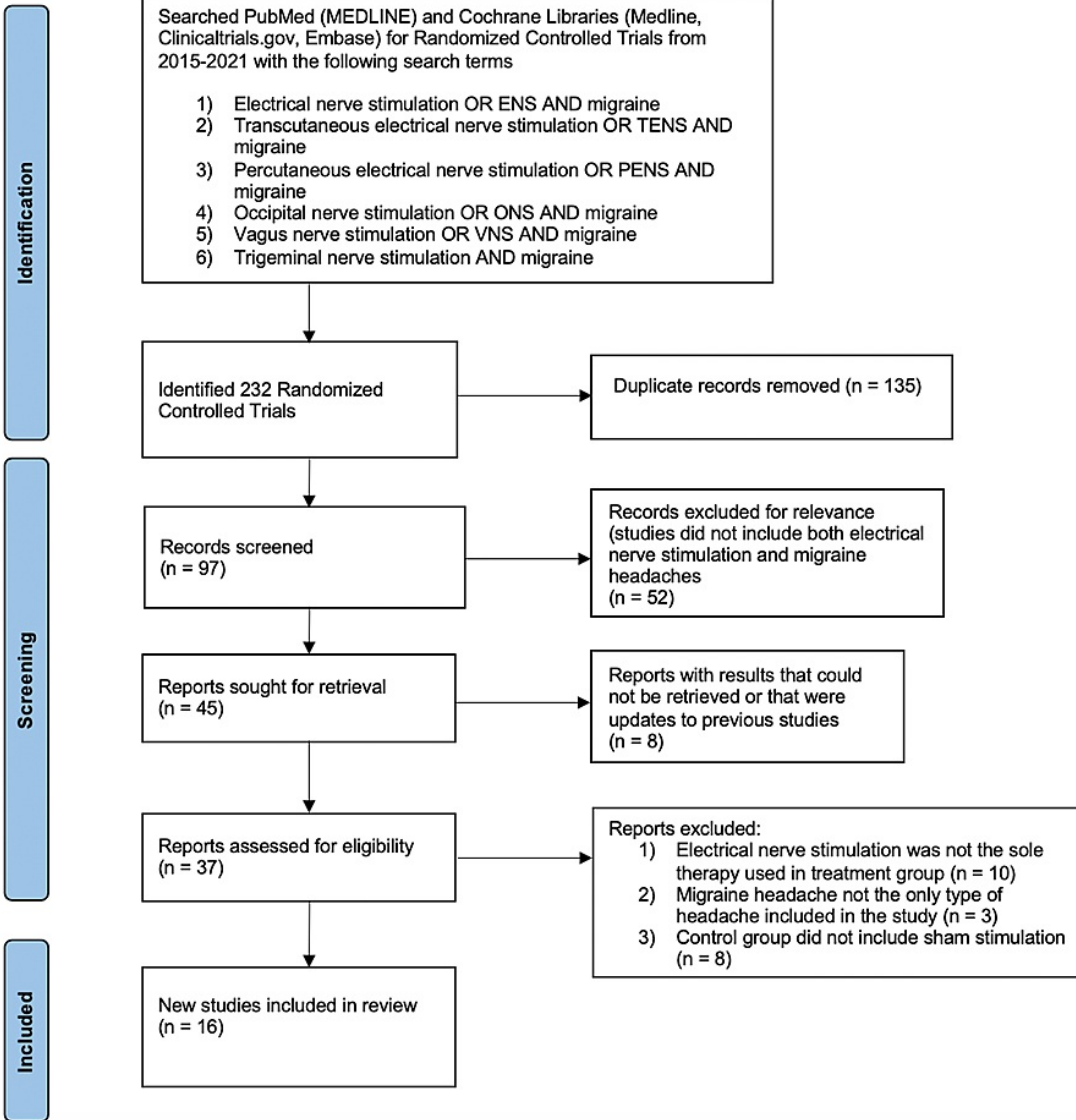

New studies included in review $(n=16)$

FIGURE 2: Search Strategy 


\section{Cureus}

\section{Author/Year Intervention/Control \\ Percutaneous electrical \\ $\mathrm{Li}$ and $\mathrm{Xu}$ \\ 2017 [18] \\ Yarnitsky et \\ al. 2019 [19] \\ Remote electrical \\ neuromodulation (REN) \\ versus sham}

Chou et al. Trigeminal neurostimulation

2019 [20] (TNS) versus sham

Hokenek et

al. 2021 [21]

Mekhail et

al. 2017 [22]

Dodick et al.

2015 [23]

Slotty et al.

2015 [24]

Danno et al.

2019 [25

Tassorelli et

al. 2018 [26]

Diener et al.

2019 [27]

Blech et al. 2020 [28]

Grazzi et al. 2018 [29]

Martelletti et al. 2018 [30]

Silberstein et al. 2016 [31]

Liu et al.

2017 [32]

Lendvai et al. 2020 [11]
ONS versus sham

TENS versus sham

ONS versus sham

ONS versus subthreshold stimulation

Supraorbital transcutaneous nerve stimulation versus sham

Non-invasive vagus nerve stimulation (nVNS) versus sham

nVNS versus sham

nVNS versus sham

nVNS versus sham

nVNS versus sham

nVNS versus sham

Transcutaneous occipital nerve stimulation (tONS) (2 $\mathrm{Hz}, 2 \mathrm{~Hz} / 100 \mathrm{~Hz}, 100 \mathrm{~Hz}$ ) versus sham versus topiramate

VNS versus sham
Result

Significant decrease in monthly migraine days, monthly headache attacks, and use of antimigraine drugs with electrodes were placed at the bilateral Taiyang points.

REN, which was placed on the upper lateral portion of the arm, was more effective than sham in reducing pain associated with migraines and the "most bothersome symptoms" of migraines. Pain-free percentages were $37.4 \%$ REN vs. $18.4 \%$ sham, and most bothersome symptom relief percentages were $46.3 \%$ REN vs. $22.2 \%$ sham

Significant difference in pain reduction in those who suffered migraine without auras, but no difference in pain reduction for those who suffered from migraine with auras. Changes in the visual analog scale (VAS) for migraine without auras were $-3.3 \pm 2.4$ for the TNS group versus $-1.7 \pm 1.9$ for the sham group

Significant decrease in pain intensity associated with migraines in the TENS group compared to the sham group. Changes in VAS scores were as follows: $-65 \pm 25$ for TENS and $-9 \pm 2$ for the sham group

Average reduction of 8.51 headache days per month in ONS group compared to sham

Average reduction of $6.7+/-8.4$ headache days per month; $65.4 \%$ of participants reported excellent or good headache relief with ONS compared to sham

Significant improvements reported in pain threshold of suprathreshold stimulation versus subthreshold $(1.98 \pm 1.56$ vs. $5.65 \pm 2.11)$ on the VAS

Significant decrease in the number of migraine attacks (5.33 vs. 3.94), in the number of migraine days per month ( 8.16 vs. 6.84$)$, decrease in number of days per month a patient takes migraine drugs ( 8.75 vs. 7.83 ) in the supraorbital transcutaneous stimulation group

nVNS was superior to sham in reducing pain at 30 minutes $(12.7 \%$ vs $4.2 \% ; p=0.012)$ and 60 minutes $(21.0 \%$ vs $10.0 \%$; $p=0.023)$, but not at 120 minutes $(30.4 \%$ vs $19.7 \% ; p=$ $0.067)$. Total pain-free percentage difference between the nVNS group and sham group was $13.7 \%$

Mean reduction in headache days per month was 2.27 for the nVNS group compared to 1.53 for the sham group $(p=0.0043)$

No significant differences were found at 120 minutes in pain freedom between sham and nVNS group ( $30.4 \%$ for nVNS vs. $19.7 \%$ for sham; $p=0.067$ ). Significant differences were found in pain freedom between the two groups at 30 minutes and 60 minutes and greater pain relief was reported in the nNVS group at 120 minutes

Significant decrease in pain intensity at 30 minutes (nVNS, $32.2 \%$; sham, $18.5 \% ; p=0.020$ ), 60 minutes (nVNS, 38.8\%; sham, 24.0\%; $p=0.017$ ), and 120 minutes (nVNS, $46.8 \%$; sham, $26.2 \% ; p=0.002$ ). Decrease in those who required medication for their migraines (nVNS, $59.3 \%$; sham, $41.9 \% ; p=0.013$ )

Patients in the nVNS group reported more pain-free attacks with 60 minutes $(p=0.025)$ and 120 minutes of treatment $(p=0.018)$ compared to the sham group. There was also significant reduction in pain associated with migraines for both those in the 60- and 120minute treatment groups ( $p=0.029$ vs. 0.011 , respectively) compared to the sham group

Mean change in the nNVS group in headache days was -7.9 (95\% confidence interval: -11.9 to $-3.8 ; p<0.01$ )

Endpoints were reported as follows: headache days (significant reductions in both the 100 $\mathrm{Hz}$ tONS group and topiramate), duration, intensity (equal among all five groups: $2 \mathrm{~Hz}, 2$ $\mathrm{Hz} / 100 \mathrm{~Hz}, 100 \mathrm{~Hz}$, sham, and topiramate), and $50 \%$ responder rates (significant reductions equal among all tONS stimulation groups and topiramate)

Decreased number of severe migraine attacks per month, but no decreases in total attacks/month or headache days/month between VNS and sham groups

\section{TABLE 1: Summary of included randomized control trials}

PENS: percutaneous electrical nerve stimulation; REN: remote electrical neuromodulation; TNS: trigeminal neurostimulation; TENS: transcutaneous 


\section{Cureus}

electrical nerve stimulation; VAS: visual analog scale; ONS: occipital nerve stimulation; nVNS: non-invasive vagus nerve stimulation; tONS: transcutaneous occipital nerve stimulation; VNS: vagus nerve stimulation

\begin{tabular}{|c|c|c|c|c|c|c|c|}
\hline $\begin{array}{l}\text { Author } \\
\text { name/year }\end{array}$ & $\begin{array}{l}\text { Random sequence } \\
\text { generation (selection } \\
\text { bias) }\end{array}$ & $\begin{array}{l}\text { Allocation } \\
\text { concealment } \\
\text { (selection bias) }\end{array}$ & $\begin{array}{l}\text { Blinding of participants } \\
\text { and personal (performance } \\
\text { bias) }\end{array}$ & $\begin{array}{l}\text { Blinding of } \\
\text { outcome } \\
\text { Assessments }\end{array}$ & $\begin{array}{l}\text { Incomplete } \\
\text { data } \\
\text { outcome }\end{array}$ & $\begin{array}{l}\text { Selective } \\
\text { reporting }\end{array}$ & $\begin{array}{l}\text { Other } \\
\text { bias }\end{array}$ \\
\hline $\begin{array}{l}\text { Li and Xu } \\
2017 \text { [18] }\end{array}$ & Low risk of bias & Low risk of bias & Low risk of bias & Low risk of bias & $\begin{array}{l}\text { Low risk of } \\
\text { bias }\end{array}$ & $\begin{array}{l}\text { Low risk } \\
\text { of bias }\end{array}$ & $\begin{array}{l}\text { Low risk } \\
\text { of bias }\end{array}$ \\
\hline $\begin{array}{l}\text { Yarnitsky et } \\
\text { al. } 2019 \\
{[19]}\end{array}$ & Low risk of bias & Low risk of bias & Low risk of bias & Low risk of bias & $\begin{array}{l}\text { Low risk of } \\
\text { bias }\end{array}$ & $\begin{array}{l}\text { Low risk } \\
\text { of bias }\end{array}$ & $\begin{array}{l}\text { Low risk } \\
\text { of bias }\end{array}$ \\
\hline $\begin{array}{l}\text { Chou et al. } \\
2019 \text { [20] }\end{array}$ & Low risk of bias & Low risk of bias & Low risk of bias & Low risk of bias & $\begin{array}{l}\text { Low risk of } \\
\text { bias }\end{array}$ & $\begin{array}{l}\text { Low risk } \\
\text { of bias }\end{array}$ & $\begin{array}{l}\text { Low risk } \\
\text { of bias }\end{array}$ \\
\hline $\begin{array}{l}\text { Hokenek et } \\
\text { al. } 2021 \\
\text { [21] }\end{array}$ & Low risk of bias & Low risk of bias & Low risk of bias & Low risk of bias & $\begin{array}{l}\text { Low risk of } \\
\text { bias }\end{array}$ & $\begin{array}{l}\text { Low risk } \\
\text { of bias }\end{array}$ & $\begin{array}{l}\text { Low risk } \\
\text { of bias }\end{array}$ \\
\hline $\begin{array}{l}\text { Mekhail et } \\
\text { al. } 2017 \\
\text { [22] }\end{array}$ & Low risk of bias & Low risk of bias & Low risk of bias & Low risk of bias & $\begin{array}{l}\text { Low risk of } \\
\text { bias }\end{array}$ & $\begin{array}{l}\text { Low risk } \\
\text { of bias }\end{array}$ & $\begin{array}{l}\text { Unknown } \\
\text { risk of } \\
\text { bias* }\end{array}$ \\
\hline $\begin{array}{l}\text { Dodick et } \\
\text { al. } 2015 \\
\text { [23] }\end{array}$ & Low risk of bias & Low risk of bias & Low risk of bias & Low risk of bias & $\begin{array}{l}\text { Low risk of } \\
\text { bias }\end{array}$ & $\begin{array}{l}\text { Low risk } \\
\text { of bias }\end{array}$ & $\begin{array}{l}\text { Unknown } \\
\text { risk of } \\
\text { bias** }^{*}\end{array}$ \\
\hline $\begin{array}{l}\text { Slotty et al. } \\
2015 \text { [24] }\end{array}$ & Low risk of bias & Low risk of bias & Low risk of bias & Low risk of bias & $\begin{array}{l}\text { Low risk of } \\
\text { bias }\end{array}$ & $\begin{array}{l}\text { Low risk } \\
\text { of bias }\end{array}$ & $\begin{array}{l}\text { Low risk } \\
\text { of bias }\end{array}$ \\
\hline $\begin{array}{l}\text { Danno et } \\
\text { al. } 2019 \\
{[25]}\end{array}$ & Low risk of bias & Low risk of bias & Low risk of bias & Low risk of bias & $\begin{array}{l}\text { Low risk of } \\
\text { bias }\end{array}$ & $\begin{array}{l}\text { Low risk } \\
\text { of bias }\end{array}$ & $\begin{array}{l}\text { Low risk } \\
\text { of bias }\end{array}$ \\
\hline $\begin{array}{l}\text { Tassorelli } \\
\text { et al. } 2018 \\
{[26]}\end{array}$ & Low risk of bias & Low risk of bias & Low risk of bias & Low risk of bias & $\begin{array}{l}\text { Low risk of } \\
\text { bias }\end{array}$ & $\begin{array}{l}\text { Low risk } \\
\text { of bias }\end{array}$ & $\begin{array}{l}\text { Low risk } \\
\text { of bias }\end{array}$ \\
\hline $\begin{array}{l}\text { Diener et } \\
\text { al. } 2019 \\
{[27]}\end{array}$ & Low risk of bias & Low risk of bias & Low risk of bias & Low risk of bias & $\begin{array}{l}\text { Low risk of } \\
\text { bias }\end{array}$ & $\begin{array}{l}\text { Low risk } \\
\text { of bias }\end{array}$ & $\begin{array}{l}\text { Unknown } \\
\text { risk of } \\
\text { bias }\end{array}$ \\
\hline $\begin{array}{l}\text { Blech et al. } \\
2020 \text { [28] }\end{array}$ & Low risk of bias & Low risk of bias & Low risk of bias & Low risk of bias & $\begin{array}{l}\text { Low risk of } \\
\text { bias }\end{array}$ & $\begin{array}{l}\text { Low risk } \\
\text { of bias }\end{array}$ & $\begin{array}{l}\text { Low risk } \\
\text { of bias }\end{array}$ \\
\hline $\begin{array}{l}\text { Grazzi et } \\
\text { al. } 2018 \\
\text { [29] }\end{array}$ & Low risk of bias & Low risk of bias & Low risk of bias & Low risk of bias & $\begin{array}{l}\text { Low risk of } \\
\text { bias }\end{array}$ & $\begin{array}{l}\text { Low risk } \\
\text { of bias }\end{array}$ & $\begin{array}{l}\text { Low risk } \\
\text { of bias }\end{array}$ \\
\hline $\begin{array}{l}\text { Martelletti } \\
\text { et al. } 2018 \\
\text { [30] }\end{array}$ & Low risk of bias & Low risk of bias & Low risk of bias & Low risk of bias & $\begin{array}{l}\text { Low risk of } \\
\text { bias }\end{array}$ & $\begin{array}{l}\text { Low risk } \\
\text { of bias }\end{array}$ & $\begin{array}{l}\text { Unknown } \\
\text { risk of } \\
\text { bias* }^{*}\end{array}$ \\
\hline $\begin{array}{l}\text { Silberstein } \\
\text { et al. } 2016 \\
\text { [31] }\end{array}$ & Low risk of bias & Low risk of bias & Low risk of bias & Low risk of bias & $\begin{array}{l}\text { Low risk of } \\
\text { bias }\end{array}$ & $\begin{array}{l}\text { Low risk } \\
\text { of bias }\end{array}$ & $\begin{array}{l}\text { Unknown } \\
\text { risk of } \\
\text { bias* }^{*}\end{array}$ \\
\hline $\begin{array}{l}\text { Liu et al. } \\
2017 \text { [32] }\end{array}$ & Low risk of bias & Low risk of bias & Low risk of bias & Low risk of bias & $\begin{array}{l}\text { Low risk of } \\
\text { bias }\end{array}$ & $\begin{array}{l}\text { Low risk } \\
\text { of bias }\end{array}$ & $\begin{array}{l}\text { Low risk } \\
\text { of bias }\end{array}$ \\
\hline $\begin{array}{l}\text { Lendvai et } \\
\text { al. } 2020 \\
{[11]}\end{array}$ & Low risk of bias & Low risk of bias & Low risk of bias & Low risk of bias & $\begin{array}{l}\text { Low risk of } \\
\text { bias }\end{array}$ & $\begin{array}{l}\text { Low risk } \\
\text { of bias }\end{array}$ & $\begin{array}{l}\text { Low risk } \\
\text { of bias }\end{array}$ \\
\hline
\end{tabular}

TABLE 2: Cochrane Collaboration's risk of bias 


\title{
Cureus
}

\author{
Justification for any categories not receiving "low risk of bias" \\ * Had an open-label phase of the study \\ ** $70 \%$ of participants reported having an adverse event, with $40.7 \%$ requiring hospitalization
}

We attempted to conduct a meta-analysis on the studies included in our systematic review, however this was not possible because of the heterogeneity of the studies, as we focused on all types of ENS rather than one in particular. However, in the future we plan on conducting a more detailed follow-up analysis of each type of electrical nerve stimulation individually. We will also not limit our search to RCTs, and instead include all types of studies.

\section{Results \\ Discussion}

Based on all of the studies included in our systematic review, there was a near-consensus that ENS had a significant therapeutic benefit for those who suffer from chronic migraines. Numerous studies in our analysis reported decreases in the VAS, mean number of headache days, severity of attacks, and pain associated with migraines in the groups that received ENS treatment compared to those who received sham stimulation [18-32]. Only two studies reported no significant differences between ENS and sham in one or more of their endpoints $[11,20]$. Interestingly, one of these two studies found no significant differences only in the subgroup of patients who suffered migraines with auras. In the other subgroup, those who suffered from migraines without auras, ENS was shown to have a therapeutic effect [20]. The other studies included in our systematic review did not draw a distinction between the subtypes of migraines. As a result, it is still yet to be determined if these results were due to natural variation in the population analyzed or a result of the differences in pathophysiologies of migraines with and without auras.

Of note, a study conducted by Liu et al. found that using a $100 \mathrm{~Hz}$ frequency to treat migraine-associated symptoms had similar results to using topiramate [32]. Additionally, a study conducted by Rapoport et al. also presented similar findings. The researchers in this study determined a non-inferiority of REN compared to the conventional pharmacological treatments in completely relieving all migraine-associated pain [33]. While more studies of this nature are needed, specifically non-inferiority trials, to corroborate these findings, the results of these studies are rather encouraging. Among the most prevalent issues in migraine disorders are drug-induced side effects. Chronic use of drugs such as aspirin can cause stroke, gastrointestinal bleeding, and stomach ulcers while chronic topiramate use can cause blurry vision, fatigue, and memory issues [6, 7]. ENS may serve a beneficial role in that it not only has a very narrow side effect profile outside of hardware malfunctions, but also has very few contraindications [34]. In addition, ENS units may help to drive down costs associated with chronic migraine symptoms. After all, on average, a TENS unit ranges from $\$ 20$ to $\$ 100$ in price and is a one-time-only purchase [35] Furthermore, another study found that an ONS unit reduces cost by $\$ 1,577$ annually compared to conventional treatments for certain types of headaches [36]. In contrast, the current average cost of chronic migraine treatment ranges between $\$ 8,500$ and $\$ 9,500$ and accounts for $\$ 13$ to $\$ 17$ billion in the United States annually [37, 38].

Overall, the positive results found in our study may stem from improvements in technologies and our understanding of both the mechanisms behind ENS and the pathophysiology of migraines. As mentioned above, ENS may be administered through a wide range of frequencies (from $1 \mathrm{~Hz}$ to $100 \mathrm{~Hz}$ ). These wide ranges of frequencies work through various different mechanisms which may influence therapeutic outcomes. For example, in TENS, high-frequency stimulation is thought to inhibit pain according to the gate control theory of pain, while low-frequency stimulation is thought to work through the modulation of opioid receptors, GABA receptors, and serotonin receptors in the periaqueductal gray, rostral ventral medulla, and spinal cord $[39,40]$. Previous studies that found inconclusive results may have used frequencies that were not therapeutically optimal. Only recently have we begun discovering which stimulation frequencies may be ideal to treat migraines. For example, in a direct comparison study published in 2015 between $1 \mathrm{~Hz}$ and $25 \mathrm{~Hz}$ frequencies, researchers found that using a $1 \mathrm{~Hz}$ frequency to treat migraines resulted in a significantly larger reduction in mean headache days compared to treatment with a $25 \mathrm{~Hz}$ frequency ( $-7.0 \pm 4.6$ vs. $-3.3 \pm 5.4$ days) [41]. Furthermore, even though various methods of ENS, such as VNS, have been present for a while, the vast majority of RCTs regarding ENS have taken place during the last half decade. The data gathered as a result of these trials has allowed for a better understanding of the underlying mechanisms of ENS and their optimal settings.

\section{Conclusions}

While more research needs to be conducted in order to fully understand the nuances of electrical nerve stimulators, they may indeed serve as a viable therapeutic intervention for migraines. Although previous studies have shown mixed efficacy with the use of ENS, technological advances and improvements in our clinical knowledge have resulted in significant improvements to electrical nerve stimulators. The results of our study, which included 18 separate RCTs, are encouraging in that it showed a near-consensus that ENS 
was effective. As a result, if this trend among studies continues, those who suffer from migraines will have an affordable treatment option, free of the negative side effects associated with commonly used migraine medications.

\section{Additional Information \\ Disclosures}

Conflicts of interest: In compliance with the ICMJE uniform disclosure form, all authors declare the following: Payment/services info: All authors have declared that no financial support was received from any organization for the submitted work. Financial relationships: All authors have declared that they have no financial relationships at present or within the previous three years with any organizations that might have an interest in the submitted work. Other relationships: All authors have declared that there are no other relationships or activities that could appear to have influenced the submitted work.

\section{References}

1. Russell MB, Iselius L, Olesen J: Inheritance of migraine investigated by complex segregation analysis . Hum Genet. 1995, 96:726-30. 10.1007/BF00210307

2. Friedman DI, De ver Dye T: Migraine and the environment. Headache. 2009, 49:941-52. 10.1111/j.15264610.2009.01443.x

3. Pathophysiology, clinical manifestations, and diagnosis of migraine in adults . (2020). Accessed: July 15, 2021: https://www.uptodate.com/contents/pathophysiology-clinical-manifestations-and-diagnosis-ofmigraine-in-adults.

4. Dodick DW: A phase-by-phase review of migraine pathophysiology . Headache. 2018, 58:4-16. 10.1111/head.13300

5. Sjaastad O, Bovim G: Cervicogenic headache. The differentiation from common migraine. An overview . Funct Neurol. 1991, 6:93-100.

6. Drugs and supplements topirmate (oral route) . (2021). Accessed: July 15, 2021: https://www.mayoclinic.org/drugs-supplements/topiramate-oral-route/side-effects/drg-20067047.

7. Daily aspirin therapy: understand the benefits and risks . (2019). Accessed: July 15, 2021: https://www.mayoclinic.org/diseases-conditions/heart-disease/in-depth/daily-aspirin-therapy/art20046797..

8. Jones I, Johnson MI: Transcutaneous electrical nerve stimulation. Cont Educ Anaesth Crit Care Pain. 2009, 9:130-5. 10.1093/bjaceaccp/mkp021

9. Transcutaneous electrical nerve stimulation. (2021). Accessed: August 8, 2021: https://en.wikipedia.org/wiki/Transcutaneous_electrical_nerve_stimulation.

10. TENS device highly effective for migraine relief in study . (2015). Accessed: July 15, 2021: https:/www.empr.com/home/news/tens-device-highly-effective-for-migraine-relief-in-study/..

11. Lendvai I, Scheele D, Hurlemann R, Buchfelder M, Kinfe T: P26 Inter-ictal molecular phenotyping of the neuro-immune axis in migraine patients under non-invasive cervical vagus nerve stimulation. Clin Neurophysiol. 2020, 131:e190-1.10.1016/j.clinph.2019.12.032

12. Lai YH, Huang YC, Huang LT, Chen RM, Chen C: Cervical noninvasive vagus nerve stimulation for migraine and cluster headache: a systematic review and meta-analysis. Neuromodulation. 2020, 23:721-31. 10.1111/ner.13122

13. Zhang Y, Liu J, Li H, et al.: Transcutaneous auricular vagus nerve stimulation at $1 \mathrm{~Hz}$ modulates locus coeruleus activity and resting state functional connectivity in patients with migraine: an fMRI study. Neuroimage Clin. 2019, 24:101971. 10.1016/j.nicl.2019.101971

14. Della Vedova C, Cathcart S, Dohnalek A, Lee V, Hutchinson MR, Immink MA, Hayball J: Peripheral interleukin-1ß levels are elevated in chronic tension-type headache patients. Pain Res Manag. 2013, 18:301-6. 10.1155/2013/796161

15. Baccouche BM, Shivkumar TE : Using SWIFT-Review as a new and robust tool for comprehensive systematic review . New Mexico J Sci. 2020, 54:14-20.

16. Welcome to the preferred reporting items for systematic reviews and meta-analyses website! . (2021). Accessed: July 14, 2021: http://www.prisma-statement.org/.

17. Sterne JA, Savović J, Page MJ, et al.: RoB 2: a revised tool for assessing risk of bias in randomised trials . BMJ. 2019, 366:14898. 10.1136/bmj.14898

18. Li H, Xu QR: Effect of percutaneous electrical nerve stimulation for the treatment of migraine . Medicine (Baltimore). 2017, 96:e8108. 10.1097/MD.0000000000008108

19. Yarnitsky D, Dodick DW, Grosberg BM, et al.: Remote electrical neuromodulation (REN) relieves acute migraine: a randomized, double-blind, placebo-controlled, multicenter trial. Headache. 2019, 59:1240-52. 10.1111/head.13551

20. Chou DE, Shnayderman Yugrakh M, Winegarner D, Rowe V, Kuruvilla D, Schoenen J: Acute migraine therapy with external trigeminal neurostimulation (ACME): a randomized controlled trial. Cephalalgia. 2019, 39:3-14. 10.1177/0333102418811573

21. Hokenek NM, Erdogan MO, Hokenek UD, Algin A, Tekyol D, Seyhan AU: Treatment of migraine attacks by transcutaneous electrical nerve stimulation in emergency department: a randomize controlled trial. Am J Emerg Med. 2021, 39:80-5. 10.1016/j.ajem.2020.01.024

22. Mekhail NA, Estemalik E, Azer G, Davis K, Tepper SI: Safety and efficacy of occipital nerves stimulation for the treatment of chronic migraines: randomized, double-blind, controlled single-center experience. Pain Pract. 2017, 17:669-77. 10.1111/papr.12504

23. Dodick DW, Silberstein SD, Reed KL, et al.: Safety and efficacy of peripheral nerve stimulation of the occipital nerves for the management of chronic migraine: long-term results from a randomized, 
multicenter, double-blinded, controlled study. Cephalalgia. 2015, 35:344-58. 10.1177/0333102414543331

24. Slotty PJ, Bara G, Kowatz L, Gendolla A, Wille C, Schu S, Vesper J: Occipital nerve stimulation for chronic migraine: a randomized trial on subthreshold stimulation. Cephalalgia. 2015, 35:73-8.

10.1177/0333102414534082

25. Danno D, Iigaya M, Imai N, Igarashi H, Takeshima T: The safety and preventive effects of a supraorbital transcutaneous stimulator in Japanese migraine patients. Sci Rep. 2019, 9:9900. 10.1038/s41598-019-460448

26. Tassorelli C, Grazzi L, de Tommaso M, et al.: Noninvasive vagus nerve stimulation as acute therapy for migraine: the randomized PRESTO study. Neurology. 2018, 91:e364-73. 10.1212/WNL.0000000000005857

27. Diener HC, Goadsby PJ, Ashina M, et al.: Non-invasive vagus nerve stimulation (nVNS) for the preventive treatment of episodic migraine: The multicentre, double-blind, randomised, sham-controlled PREMIUM trial. Cephalalgia. 2019, 39:1475-87. 10.1177/0333102419876920

28. Blech B, Starling AJ, Marks LA, Wingerchuk DM, O'Carroll CB: Is noninvasive vagus nerve stimulation a safe and effective alternative to medication for acute migraine control?. Neurologist. 2020, 25:97-100. 10.1097/NRL.0000000000000274

29. Grazzi L, Tassorelli C, de Tommaso M, et al.: Practical and clinical utility of non-invasive vagus nerve stimulation (nVNS) for the acute treatment of migraine: a post hoc analysis of the randomized, shamcontrolled, double-blind PRESTO trial. J Headache Pain. 2018, 19:98. 10.1186/s10194-018-0928-1

30. Martelletti P, Barbanti P, Grazzi L, et al.: Consistent effects of non-invasive vagus nerve stimulation (nVNS) for the acute treatment of migraine: additional findings from the randomized, sham-controlled, doubleblind PRESTO trial. J Headache Pain. 2018, 19:101. 10.1186/s10194-018-0929-0

31. Silberstein SD, Calhoun AH, Lipton RB, et al.: Chronic migraine headache prevention with noninvasive vagus nerve stimulation: the EVENT study. Neurology. 2016, 87:529-38. 10.1212/WNL.0000000000002918

32. Liu Y, Dong Z, Wang R, Ao R, Han X, Tang W, Yu S: Migraine prevention using different frequencies of transcutaneous occipital nerve stimulation: a randomized controlled trial. J Pain. 2017, 18:1006-15. 10.1016/j.jpain.2017.03.012

33. Rapoport AM, Bonner JH, Lin T, Harris D, Gruper Y, Ironi A, Cowan RP: Remote electrical neuromodulation (REN) in the acute treatment of migraine: a comparison with usual care and acute migraine medications. J Headache Pain. 2019, 20:83. 10.1186/s10194-019-1033-9

34. Transcutaneous electrical nerve stimulation (TENS). (2021). Accessed: July 15, 2021: https://my.clevelandclinic.org/health/treatments/15840-transcutaneous-electrical-nerve-stimulation-tens..

35. How to compare TENS units - a review of price \& performance . (2019). Accessed: July 15, 2021 : https://www.rsmedical.com/blog/compare-tens-units-by-price.

36. Bulsei J, Leplus A, Donnet A, et al.: Occipital nerve stimulation for refractory chronic cluster headache: a cost-effectiveness study. Neuromodulation. 2021, 10.1111/ner.13394

37. The costs of migraines detailing the costs migraine sufferers endure . (2017). Accessed: July 15, 2021: https://www.themigrainereliefcenter.com/costs-of-migraines/.

38. The cost of migraine and its treatment . (2005). Accessed: July 15, 2021: https://www.ajmc.com/view/jun052069ps62-s67.

39. Suh HR, Kim TH, Han GS: The effects of high-frequency transcutaneous electrical nerve stimulation for dental professionals with work-related musculoskeletal disorders: a single-blind randomized placebocontrolled trial. Evid Based Complement Alternat Med. 2015, 2015:327486. 10.1155/2015/327486

40. Vance CG, Dailey DL, Rakel BA, Sluka KA: Using TENS for pain control: the state of the evidence . Pain Manag. 2014, 4:197-209. 10.2217/pmt.14.13

41. Straube A, Ellrich J, Eren O, Blum B, Ruscheweyh R: Treatment of chronic migraine with transcutaneous stimulation of the auricular branch of the vagal nerve (auricular t-VNS): a randomized, monocentric clinical trial. J Headache Pain. 2015, 16:543. 10.1186/s10194-015-0543-3 